\title{
Comparison of hospitalized patients with idiopathic pulmonary fibrosis and obstructive sleep apnea outpatients in terms of general characteristics and polysomnographic features
}

\author{
(D)Bengü Şaylan \\ ${ }^{1}$ Health Sciences University, Sultan 2. Abdulhamid Han Training and Research Hospital, Department of Chest Diseases, Istanbul, Turkey
}

Cite this article as: Şaylan B. Comparison of hospitalized patients with idiopathic pulmonary fibrosis and obstructive sleep apnea outpatients in terms of general characteristics and polysomnographic features. Anatolian Curr Med J 2021; 3(3); 198-203.

\begin{abstract}
Objective: Obstructive sleep apnea (OSA) is a significant comorbidity in patients with idiopathic pulmonary fibrosis (IPF). This study aimed to evaluate the demographic and clinical characteristics of patients with and without IPF, and their polysomnographic features according to the presence and severity of OSA.

Material and Method: A total of 52 cases (29 patients hospitalized for IPF and 23 controls without IPF) admitted to the sleep laboratory with suspicion of OSA were included. Demographic, clinical data and results of polysomnographic studies were recorded from the patients' self-reports and hospital records.

Results: The distribution of sex was similar $(\mathrm{p}=0.775)$ between the patient and control groups; however, the patients with IPF were older than the controls ( 68 vs. 57 years, $p=0.003)$. The rate of current smokers was higher among the controls $(p=0.003)$, whereas dyspnea $(p<0.001)$, headache $(p=0.005)$, congestive heart failure $(p=0.013)$, pulmonary hypertension $(p<0.001)$, number of previous hospitalizations $(\mathrm{p}<0.001)$, and dust exposure $(\mathrm{p}=0.028)$ were more frequent in the IPF group. The median sleep time with $\mathrm{O}_{2}$ saturation below $90 \%$ was significantly higher in the IPF group $(\mathrm{p}<0.001)$. Among overall study population, 40 patients had OSA of whom 10 had mild, 15 had moderate, and 15 had severe OSA.

Conclusions: The co-existence of IPF significantly worsened the polysomnographic features of the patients with OSA. Further studies are needed to clarify the underlying mechanisms and to determine the optimal interventions to increase sleep quality of IPF patients.
\end{abstract}

Keywords: Idiopathic pulmonary fibrosis, obstructive sleep apnea, polysomnography, severity, hospitalization

\section{INTRODUCTION}

Obstructive sleep apnea (OSA) is a chronic disorder characterized by recurrent collapse of the upper airways during sleep and is seen in about $2-4 \%$ of the general population (1) and in about $20 \%$ of the elderly (2). The prevalence of OSA is dramatically increased in idiopathic pulmonary fibrosis (IPF), which is the most common type of idiopathic interstitial pneumonia (3). Based on the currently available literature data, about $50-90 \%$ of patients with IPF may suffer from OSA (4). It has a progressive course with a poor prognosis; the median survival is approximately three to four years (3). Besides, there is evidence that the severity of OSA is increased in patients with IPF. Previous studies showed that moderatesevere OSA, in which the apnea-hypopnea index is greater than 15 events per hour, was more frequent in IPF patients than that in the individuals without IPF $(5,6)$.
In previous years, professional associations including the American Thoracic Society, European Respiratory Society, Japanese Respiratory Society, and Latin American Thoracic Association have declared that OSA is a significant comorbidity for IPF, which has to be treated effectively as a primary goal $(5,7,8)$. Recent studies showed that OSA treatment with continuous positive airway pressure could slow down the progression of IPF $(5,9)$. Nevertheless, despite the accumulating number of studies on the topic, there are still questions yet to be answered, such as whether the exacerbation and hospitalization episodes in IPF affect the severity of OSA. Based on this background, this study aimed to evaluate the demographic and clinical characteristics of patients with and without IPF, and their polysomnographic features according to the presence and severity of OSA. 


\section{MATERIAL AND METHOD}

This study was conducted at the Department of Chest Diseases and Sleep Laboratory of theSultan 2. Abdulhamid Han Training and Research Hospital, İstanbul, Turkey. The patients who were admitted to the Department of Chest Diseases of our hospital between February and April 2020 due to interstitial lung disease, and who were stable at the time of assessment, were informed about the study. Those who gave consent to participate were included in the study group. Controls were recruited from the patients admitted to the Sleep Laboratory. The ethical committee of the İstanbul Health Sciences University of the Ministry of Health, Ümraniye Training and Research Hospital approved the study protocol (Date: 22/01/2020, Decision No: B.10.1.TKH.4.34.H.GP.0.01/8).

Polysomnographic studies were done with a 32 channel Medcare Embla A device. Electroencephalography, electrooculography, submental and bilateral tibial electromyography, and electrocardiographic recording were taken during polysomnographic sleep recordings. Airflow was measured using a nasal and oral thermistor, thoracoabdominal motion was measured with a piezoelectric belt, and saturation was measured using a pulse oximetry device. Sleep stages, desaturation, and apnea-hypopnea index (AHI) were calculated in polysomnography. The patients with an AHI $\geq 5$ per hour were diagnosed with OSA syndrome. The severity of OSA were defined as mild (AHI $\geq 5$ but $<15$ per hour), moderate (AHI $\geq 15$ but $<30$ per hour), and severe (AHI $\geq 30$ per hour).

Demographic and clinical characteristics were recorded from the patient records and hospital database management system. Clinical data included diseaserelated characteristics, comorbidities, OSA parameters, and sleep test measurements. Sleep tests for the patients with IPF were done after discharge and in the stable phase of IPF.

\section{Statistical Analysis}

Descriptive statistics were presented as number and percentage for categorical variables and median, minimum and maximum for continuous variables. Comparisons between independent groups were made using the Chi-square test for categorical data (Fisher's exact test when assumptions were not met) and the Kruskal-Wallis/Mann-Whitney U test for more than two/two groups for continuous data. Post-hoc analyses between independent groups were done with the Mann-Whitney U test with Bonferroni correction for numerical variables. All analyses were performed using PASW 18 (IBM Inc., Chicago, IL, USA), and a type-I error level of $5 \%$ was considered the statistical significance threshold.

\section{RESULTS}

A total of 52 cases; 29 patients with IPF and 23 controls were included in the study. About one-third of the patients were females in each group $(\mathrm{p}=0.775)$. The median age of the patients was higher than the controls (68 vs. 57 years, $\mathrm{p}=0.003$ ). Comparisons of demographic characteristics revealed that the median BMI $(p=0.007)$ and rate of smokers $(p=0.003)$ were higher in the control group, whereas dyspnea $(\mathrm{p}<0.001)$, headache $(p=0.005)$, congestive heart failure $(p=0.013)$, pulmonary hypertension $(\mathrm{p}<0.001)$, number of previous hospitalizations $(\mathrm{p}<0.001)$ and dust exposure $(\mathrm{p}=0.028)$ were more frequent in the patients with IPF (Table 1).

\begin{tabular}{|c|c|c|c|}
\hline & $\begin{array}{c}\text { Controls } \\
(\mathrm{n}=23)\end{array}$ & $\underset{(\mathbf{n}=29)}{\text { IPF }}$ & $\mathbf{p}$ \\
\hline Sex, n (\%) & & & 0.775 \\
\hline Male & $15(65.2)$ & $20(69.0)$ & \\
\hline Female & $8(34.8)$ & $9(31.0)$ & \\
\hline $\begin{array}{l}\text { Age, years, median } \\
\text { (min-max) }\end{array}$ & $57(47-75)$ & $68(42-91)$ & 0.003 \\
\hline $\begin{array}{l}\text { BMI, } \mathrm{kg} / \mathrm{m}^{2}, \text { median } \\
(\min -\max )\end{array}$ & $28(24-32)$ & $27(22-32)$ & 0.007 \\
\hline \multicolumn{4}{|l|}{ Smoking, n (\%) } \\
\hline Current smoker & $8(34.8)$ & $0(0.0)$ & 0.003 \\
\hline Ex-smoker & $8(34.8)$ & $17(58.6)$ & 0.087 \\
\hline Dyspnea, n (\%) & $6(26.1)$ & $27(93.1)$ & $<0.001$ \\
\hline Headache, n (\%) & $4(17.4)$ & $16(55.2)$ & 0.005 \\
\hline \multicolumn{4}{|l|}{ Comorbidities, n (\%) } \\
\hline Coronary artery disease & $2(8.7)$ & $9(31)$ & 0.086 \\
\hline $\begin{array}{l}\text { Atrial fibrillation/ } \\
\text { Arrhythmia }\end{array}$ & $3(13)$ & $3(10.3)$ & 1.000 \\
\hline Hypertension & $9(39.1)$ & $19(65.5)$ & 0.058 \\
\hline Diabetes & $8(34.8)$ & $8(27.6)$ & 0.577 \\
\hline Reflux & $6(26.1)$ & $15(51.7)$ & 0.061 \\
\hline Congestive heart failure & $0(0.0)$ & $7(24.1)$ & 0.013 \\
\hline Rheumatoid disease & $0(0.0)$ & $5(17.2)$ & 0.059 \\
\hline Pulmonary hypertension & $1(4.3)$ & $22(75.9)$ & $<0.001$ \\
\hline $\begin{array}{l}\text { Hospitalization in intensive } \\
\text { care unit, } \mathbf{n}(\%)\end{array}$ & $0(0.0)$ & $1(3.4)$ & - \\
\hline $\begin{array}{l}\text { Disease duration, years, } \\
\text { median (min-max) }\end{array}$ & - & $2(1-12)$ & - \\
\hline $\begin{array}{l}\text { Number of previous } \\
\text { hospitalizations, median } \\
\text { (min-max) }\end{array}$ & $0(0-3)$ & $2(0-8)$ & $<0.001$ \\
\hline Dust exposure, n (\%) & $2(8.7)$ & $10(34.5)$ & 0.028 \\
\hline Diagnosis, $\mathbf{n}(\%)$ & & & - \\
\hline Radiological & - & $20(69.0)$ & \\
\hline Pathological & - & $9(31.0)$ & \\
\hline
\end{tabular}

When the polysomnographic parameters were compared between patients and controls, the median sleep time with $\mathrm{O}_{2}$ saturation below $90 \%(20(0-90)$ vs. $2(0-15)$; $\mathrm{p}<0.001)$ was significantly higher in the IPF group. However, the median sleep saturation (93 (92-96) vs. 90 (81-95); $\mathrm{p}<0.001$ ), the median lowest $\mathrm{O}_{2}$ saturation (87 (69-92) vs. 80 (8-90); $\mathrm{p}=0.023)$, and the median awake $\mathrm{O}_{2}$ saturation (95 (93-97) vs. $\left.83(86-96) ; \mathrm{p}<0.001\right)$ were higher in the control group (Table 2). 
Table 2. Polysomnographic features of the study groups

\begin{tabular}{|c|c|c|c|}
\hline & $\begin{array}{c}\text { Controls } \\
(n=23)\end{array}$ & IPF $(n=29)$ & $\mathbf{p}$ \\
\hline OSA, n (\%) & $15(65.2)$ & $25(86.2)$ & 0.074 \\
\hline Mild & $4(26.7)$ & $6(24.0)$ & 0.518 \\
\hline Moderate & $4(26.7)$ & $11(44.0)$ & \\
\hline Severe & $7(46.7)$ & $8(32.0)$ & \\
\hline $\begin{array}{l}\text { Apnea-hypopnea index, } \\
\text { median (min-max) }\end{array}$ & $11(2-42)$ & $20(3-38)$ & 0.433 \\
\hline Normal, n (\%) & $8(34.8)$ & $4(13.8)$ & 0.487 \\
\hline Mild, n (\%) & $4(17.4)$ & $6(20.7)$ & \\
\hline Moderate, n (\%) & $4(17.4)$ & $10(34.5)$ & \\
\hline Severe, n (\%) & $7(30.4)$ & $9(31)$ & \\
\hline $\begin{array}{l}\text { Obstructive apnea index, } \\
\text { median (min-max) }\end{array}$ & $15(1-150)$ & $18(2-126)$ & 0.411 \\
\hline Normal, n (\%) & $10(43.5)$ & $6(20.7)$ & 0.077 \\
\hline High, n (\%) & $13(56.5)$ & $23(79.3)$ & \\
\hline $\begin{array}{l}\text { Periodic leg movement } \\
\text { index, median (min-max) }\end{array}$ & $14(2-52)$ & $9(2-81)$ & 0.306 \\
\hline Normal, n (\%) & $14(60.9)$ & $20(69)$ & 0.542 \\
\hline High, n (\%) & $9(39.1)$ & $9(31)$ & \\
\hline Oxygen use at home, $\mathrm{n}(\%)$ & - & $6(20.7)$ & - \\
\hline Total sleep time, $\min , \mathrm{n}(\%)$ & $\begin{array}{c}290 \\
(200-380)\end{array}$ & $\begin{array}{c}265 \\
(200-360)\end{array}$ & 0.337 \\
\hline $\begin{array}{l}\text { Hypopnea index, median } \\
\text { (min-max) }\end{array}$ & $8(1-32)$ & $15(1-32)$ & 0.256 \\
\hline $\begin{array}{l}\text { Oxygen desaturation index, } \\
\% \text {, median (min-max) }\end{array}$ & $7(1-36)$ & $14(2-33)$ & 0.305 \\
\hline $\begin{array}{l}\text { Sleep saturation, \%, median } \\
(\min -\max )\end{array}$ & $93(92-96)$ & $90(81-95)$ & $<0.001$ \\
\hline $\begin{array}{l}\text { Lowest } \mathrm{O}_{2} \text { saturation, } \% \text {, } \\
\text { median (min-max) }\end{array}$ & $87(69-92)$ & $80(8-90)$ & 0.023 \\
\hline $\begin{array}{l}\text { Sleep time with saturation } \\
\text { below } 90 \% \text {, min, median } \\
\text { (min-max) }\end{array}$ & $2(0-15)$ & $20(0-90)$ & $<0.001$ \\
\hline $\begin{array}{l}\text { Awake } \mathrm{O}_{2} \text { saturation, } \% \text {, } \\
\text { median (min-max) }\end{array}$ & 95 (93-97) & $93(86-96)$ & $<0.001$ \\
\hline
\end{tabular}

AHI: Apnea-hypopnea index; IPF: Idiopathic pulmonary fibrosis; OSA: Obstructive sleep apnea; Min-Max: Minimum-maximum

Among the whole group, 40 patients had OSA, and regarding disease severity, 10 patients had mild, 15 patients had moderate, and 15 patients had severe OSA. Table 3 summarizes the comparison of basal demographic characteristics between patients with and without OSA and mild-moderate-severe OSA patients. All baseline characteristics were similar according to the presence and severity of OSA. Comparison of polysomnographic features according to the severity of OSA showed a gradual worsening parallel to disease severity except for sleep saturation $(\mathrm{p}=0.239)$ and awake $\mathrm{O}_{2}$ saturation $(\mathrm{p}=0.268$; Table 4$)$.

\section{DISCUSSION}

Sleep breathing disorders, particularly OSA, possess a significant comorbidity burden for patients with IPF (10). Identifying differences regarding OSA in patients with and without IPF may provide valuable information for determining effective interventions that may improve patients' quality of life and daily living activities (5). This study showed that the polysomnographic parameters that were significantly deteriorated among patients with IPF were sleep saturation, and awake and asleep oxygen saturations. Significant decrease in $\mathrm{O}_{2}$ saturation, increase in sleep time with $\mathrm{O}_{2}$ saturation below $90 \%$, and lower awake $\mathrm{O}_{2}$ saturation are expected results, as all these parameters are associated with the pathophysiology of IPF. Besides decreases in sleep saturation, these parameters indicate a deteriorated quality of sleep and poor quality of life (11) in IPF.

Moreover, OSA is not an essential component for altered sleep quality in patients with IPF since they suffer from nocturnal hypoxia due to decreased lung volume, particularly in the supine position in sleep (12). Nocturnal hypoxia or impaired $\mathrm{O}_{2}$ saturation both in sleep and awake periods, are associated with the physiological changes in IPF. Still, OSA might also be related to these changes. Although no causative association was clearly shown between these two conditions, it was suggested that they might share common pathways. Previous studies reported that OSA might be a cause of subclinical lung injury through inspiratory resistive loads and forced inspirations against a closed glottis that cause decreased interstitial pressure, alveolar deformation, and proinflammatory capillary responses (13-16).

Polysomnographic features of patients in OSA severity categories were consistent with the grade of OSA. However, periodic leg movement index, total sleep time, sleep saturation, and awake $\mathrm{O}_{2}$ saturations were not associated with the disease severity in OSA. Among these, similar awake $\mathrm{O}_{2}$ saturations might be expected since patients with OSA may suffer from daytime fatigue or sleepiness but not decreased saturations. Nevertheless, previous studies reported that periodic leg movements and total sleep time were valuable predictors of disease severity in OSA. Periodic leg movements are involuntary, repetitive, stereotypical, and segmental movements, which may be present in approximately $6 \%$ of the general population and $65 \%$ of the older adults over 65 years $(17,18)$. Periodic leg movements may also accompany sleep disorders, including OSA (19). Previous studies showed that periodic leg movement in patients with OSA was associated with the disease severity and indicated a more risky subgroup of patients (20). Nevertheless, our results did not support this conclusion, and the periodic leg movement index was similar between OSA severity categories in our study. 


\begin{tabular}{|c|c|c|c|c|c|c|c|}
\hline & \multicolumn{3}{|c|}{ Presence of OSA } & \multicolumn{4}{|c|}{ OSA severity } \\
\hline & $\underset{(n=12)}{\text { OSA- }}$ & $\begin{array}{c}\text { OSA+ } \\
(n=40)\end{array}$ & $\mathbf{p}$ & $\underset{(n=10)}{\text { Mild }}$ & $\begin{array}{l}\text { Moderate } \\
(n=15)\end{array}$ & $\begin{array}{l}\text { Severe } \\
(n=15)\end{array}$ & $\mathbf{p}$ \\
\hline \multicolumn{8}{|l|}{ Sex, n (\%) } \\
\hline Male & $6(50.0)$ & $29(72.5)$ & 0.173 & $6(60.0)$ & $11(73.3)$ & $12(80.0)$ & 0.597 \\
\hline Female & $6(50.0)$ & $11(27.5)$ & & $4(40.0)$ & $4(26.7)$ & $3(20.0)$ & \\
\hline Age, years, median (min-max) & $57(42-83)$ & $63(43-91)$ & 0.110 & $59(43-91)$ & $67(47-81)$ & $63(49-89)$ & 0.527 \\
\hline BMI, $\mathrm{kg} / \mathrm{m}^{2}$, median $(\min -\max )$ & $27(22-30)$ & $27(22-32)$ & 0.921 & $28(22-32)$ & $26(23-30)$ & $28(22-32)$ & 0.205 \\
\hline \multicolumn{8}{|l|}{ Smoking, n (\%) } \\
\hline Current smoker & $2(28.6)$ & $6(30.0)$ & 1.000 & $3(75.0)$ & $1(11.1)$ & $2(28.6)$ & - \\
\hline Ex-smoker & $5(41.7)$ & $20(50.0)$ & 0.612 & $6(60.0)$ & $6(40.0)$ & $8(53.3)$ & 0.587 \\
\hline $\begin{array}{l}\text { Disease duration, years, median (min- } \\
\max \text { ) }\end{array}$ & $2(1-4)$ & $2(1-12)$ & 0.425 & $4(1-5)$ & $2(1-12)$ & $2(1-4)$ & 0.371 \\
\hline Previous hospitalization, $\mathrm{n}(\%)$ & $4(33.3)$ & $25(62.5)$ & 0.102 & $6(60.0)$ & $11(73.3)$ & $8(53.3)$ & 0.591 \\
\hline $\begin{array}{l}\text { Previous "clinical" hospitalization, } \\
\text { median (min-max) }\end{array}$ & $0(0-4)$ & $2(0-8)$ & 0.033 & $1.5(0-6)$ & $2(0-6)$ & $2(0-8)$ & 0.616 \\
\hline $\begin{array}{l}\text { Hospitalization in intensive care unit, } \\
\mathrm{n}(\%)\end{array}$ & $0(0.0)$ & $1(2.5)$ & - & $0(0.0)$ & $1(6.7)$ & $0(0.0)$ & 1.000 \\
\hline Dyspnea, n (\%) & $4(33.3)$ & $29(72.5)$ & 0.019 & $7(70.0)$ & $12(80.0)$ & $10(66.7)$ & 0.749 \\
\hline Headache, n (\%) & $3(25.0)$ & $17(42.5)$ & 0.330 & $4(40.0)$ & $7(46.7)$ & $6(40.0)$ & 0.918 \\
\hline \multicolumn{8}{|l|}{ Comorbidities, n (\%) } \\
\hline Coronary artery disease & $1(8.3)$ & $10(25.0)$ & 0.421 & $0(0.0)$ & $5(33.3)$ & $5(33.3)$ & 0.161 \\
\hline Atrial fibrillation/Arrhythmia & $0(0.0)$ & $6(15.0)$ & 0.316 & $2(20.0)$ & $2(13.3)$ & $2(13.3)$ & 1.000 \\
\hline Hypertension & $5(41.7)$ & $23(57.5)$ & 0.510 & $5(50.0)$ & $10(66.7)$ & $8(53.3)$ & 0.653 \\
\hline Diabetes & $1(8.3)$ & $15(37.5)$ & 0.078 & $4(40.0)$ & $6(40.0)$ & $5(33.3)$ & 0.915 \\
\hline Gastroesophageal reflux disease & $4(33.3)$ & $17(42.5)$ & 0.741 & $3(30.0)$ & $7(46.7)$ & $7(46.7)$ & 0.653 \\
\hline Congestive heart failure & $0(0.0)$ & $7(17.5)$ & 0.181 & $0(0.0)$ & $4(26.7)$ & $3(20)$ & 0.244 \\
\hline Rheumatoid disease & $0(0.0)$ & $5(12.5)$ & 0.578 & $3(30.0)$ & $2(13.3)$ & $0(0.0)$ & - \\
\hline Pulmonary hypertension & $2(16.7)$ & $21(52.5)$ & 0.046 & $4(40.0)$ & $9(60.0)$ & $8(53.3)$ & 0.616 \\
\hline Dust exposure, $\mathrm{n}(\%)$ & $0(0.0)$ & $12(30.0)$ & 0.047 & $2(20.0)$ & $5(33.3)$ & $5(33.3)$ & 0.829 \\
\hline Diagnosis, $\mathrm{n}(\%)$ & & & 0.076 & & & & 0.307 \\
\hline Radiological & $1(25.0)$ & $19(76.0)$ & & $6(100.0)$ & $7(63.6)$ & $6(75.0)$ & \\
\hline Pathological & $3(75.0)$ & $6(24.0)$ & & $0(0.0)$ & $4(36.4)$ & $2(25.0)$ & \\
\hline
\end{tabular}

Table 4. Polysomnographic characteristics according to the presence and severity of obstructive sleep apnea

\begin{tabular}{|c|c|c|c|c|c|c|c|}
\hline & \multicolumn{3}{|c|}{ Presence of OSA } & \multicolumn{4}{|c|}{ OSA Severity } \\
\hline & $\begin{array}{l}\text { OSA- } \\
(n=12)\end{array}$ & $\begin{array}{c}\text { OSA+ } \\
(n=40)\end{array}$ & $\mathbf{p}$ & $\begin{array}{c}\text { Mild } \\
(\mathbf{n}=10)\end{array}$ & $\begin{array}{l}\text { Moderate } \\
(n=15)\end{array}$ & $\begin{array}{l}\text { Severe } \\
(\mathrm{n}=15)\end{array}$ & $\mathbf{p}$ \\
\hline AHI, median (Q1-Q3) & $3(2-4)$ & $22(6-42)$ & $<0.001$ & $8(6-11)$ & $20(15-30)$ & $35(31-42)$ & $<0.001$ \\
\hline Mild, n (\%) & $0(0.0)$ & $10(25.0)$ & & $10(100.0)$ & $0(0.0)$ & $0(0.0)$ & \\
\hline Moderate, n (\%) & $0(0.0)$ & $14(35.0)$ & & $0(0.0)$ & $14(93.3)$ & $0(0.0)$ & \\
\hline Severe, $\mathrm{n}(\%)$ & $0(0.0)$ & $16(40.0)$ & & $0(0.0)$ & $1(6.7)$ & $15(100.0)$ & \\
\hline Normal, n (\%) & $12(100.0)$ & $4(10.0)$ & $<0.001$ & $4(40.0)$ & $0(0.0)$ & $0(0.0)$ & - \\
\hline High, n (\%) & $0(0.0)$ & $36(90.0)$ & & $6(60.0)$ & $15(100.0)$ & $15(100.0)$ & \\
\hline $\begin{array}{l}\text { Periodic leg movement index, } \\
\text { median (min-max) }\end{array}$ & $14(2-30)$ & $9.5(2-81)$ & 0.974 & $9(2-81)$ & $7(2-48)$ & $12(2.1-52)$ & 0.773 \\
\hline Normal, n (\%) & $8(66.7)$ & $26(65.0)$ & 1.000 & $7(70.0)$ & $11(73.3)$ & $8(53.3)$ & 0.481 \\
\hline High, n (\%) & $4(33.3)$ & $14(35.0)$ & & $3(30.0)$ & $4(26.7)$ & $7(46.7)$ & \\
\hline $\begin{array}{l}\text { Total sleep time, min, median } \\
(\min -\max )\end{array}$ & $265(200-380)$ & $273(200-380)$ & 0.695 & $283(200-360)$ & $266(245-380)$ & $280(210-360)$ & 0.696 \\
\hline $\begin{array}{l}\text { Hypopnea index, median (min- } \\
\text { max) }\end{array}$ & $2.5(1-4)$ & $16(3-32)$ & $<0.001$ & $6.5(3-20)$ & $16(10-22)$ & $21(8-32)$ & $<0.001$ \\
\hline $\begin{array}{l}\text { Oxygen desaturation index, } \\
\text { median (min-max) }\end{array}$ & $2(1-5)$ & $17(3-36)$ & $<0.001$ & $6(3-8)$ & $16(5-25)$ & $25(12-36)$ & $<0.001$ \\
\hline $\begin{array}{l}\text { Average sleep saturation, } \% \text {, } \\
\text { median (min-max) }\end{array}$ & $93(90-96)$ & $92(81-95)$ & 0.024 & $93(83-95)$ & $91(81-95)$ & $90(82-95)$ & 0.239 \\
\hline $\begin{array}{l}\text { Lowest O2 saturation, \%, median } \\
\text { (Q1-Q3) }\end{array}$ & $90(85-92)$ & $81(8-90)$ & $<0.001$ & $88(77-90)$ & $83(8-88)$ & $78(67-87)$ & 0.004 \\
\hline $\begin{array}{l}\text { Sleep time with saturation below } \\
90 \%, \text { min, median (min-max) }\end{array}$ & $1(0-8)$ & $11(0-90)$ & $<0.001$ & $3(0-80)$ & $15(3-90)$ & $20(2-90)$ & 0.029 \\
\hline $\begin{array}{l}\text { Awake O2 saturation, } \% \text {, median } \\
(\text { min-max) }\end{array}$ & $95(92-97)$ & $94(86-96)$ & 0.004 & $95(90-96)$ & $93(89-95)$ & $94(86-95)$ & 0.268 \\
\hline
\end{tabular}


Likewise, total sleep time was also suggested to be associated with the disease severity in OSA. This conclusion was based on the association of total sleep time with the high-sensitivity C-reactive protein, a significant indicator of chronic intermittent hypoxia in patients with OSA. Multivariate analyses showed that total sleep time was a stronger predictor of highsensitivity C-reactive protein variability than the apneahypopnea index, which is the gold-standard indicator of OSA severity (21). Our results were contrary to this evidence, in which the total sleep time was not associated with OSA severity. This might be related to patient selection for the analysis because the OSA group included patients both with and without IPF, which may alleviate the importance of total sleep time to predict OSA's severity.

\section{CONCLUSION}

Idiopathic pulmonary fibrosis is a chronic debilitating disease with poor prognosis and a significantly deteriorated quality of life. Patients with IPF and comorbid OSA are at increased risk of severe disease outcomes. OSA is known to impair the quality of life, and this study showed that the co-existing IPF significantly worsens polysomnographic features in these patients. Further comparison studies that includes increased number of patients and healthy individuals are needed. These studies may help to clarify the mechanisms that additively deteriorate these pathways and to determine the optimal interventions to increase sleep quality and subsequent quality of life of IPF patients.

\section{ETHICAL DECLARATIONS}

Ethics Committee Approval: The ethical committee of the İstanbul Health Sciences University of the Ministry of Health, Ümraniye Training and Research Hospital approved the study protocol (Date: 22/01/2020, Decision No: B.10.1.TKH.4.34.H.GP.0.01/8).

Informed Consent: All patients signed the free and informed consent form.

Referee Evaluation Process: Externally peer-reviewed.

Conflict of Interest Statement: The authors have no conflicts of interest to declare.

Financial Disclosure: The authors declared that this study has received no financial support.

Author Contributions: All of the authors declare that they have all participated in the design, execution, and analysis of the paper, and that they have approved the final version.

\section{REFERENCES}

1. Spicuzza L, Caruso D, Di Maria G. Obstructive sleep apnoea syndrome and its management. Ther Adv Chronic Dis 2015; 6: 273-85.

2. Hiestand DM, Britz P, Goldman M, Phillips B. Prevalence of symptoms and risk of sleep apnea in the US population: Results from the national sleep foundation sleep in America 2005 poll. Chest 2006; 130: 780-6.

3. Raghu G, Remy-Jardin M, Myers JL, et al. Diagnosis of Idiopathic Pulmonary Fibrosis. An Official ATS/ERS/JRS/ALAT Clinical Practice Guideline. Am J Respir Crit Care Med 2018; 198: e44-e68.

4. Schiza SE, Bouloukaki I, Bolaki M, Antoniou KM. Obstructive sleep apnea in pulmonary fibrosis. Curr Opin Pulm Med 2020; 26: $443-8$

5. Mermigkis C, Bouloukaki I, Antoniou K, et al. Obstructive sleep apnea should be treated in patients with idiopathic pulmonary fibrosis. Sleep Breath 2015; 19: 385-91.

6. Gille T, Didier M, Boubaya M, et al. Obstructive sleep apnoea and related comorbidities in incident idiopathic pulmonary fibrosis. Eur Respir J 2017; 49: 1601934.

7. King C, Nathan SD. Identification and treatment of comorbidities in idiopathic pulmonary fibrosis and other fibrotic lung diseases. Curr Opin Pulm Med 2013; 19: 466-73.

8. Mermigkis C, Bouloukaki I, Antoniou K, et al. Obstructive sleep apnea should be treated in patients with idiopathic pulmonary fibrosis. Sleep Breath 2015; 19: 385-91.

9. Gille T, Didier M, Boubaya M, et al., Natural history of idiopathic pulmonary fibrosis (IPF) associated with obstructive sleep apnea (OSA) with or without continuous positive airway pressure (CPAP), in Idiopathic interstitial pneumonias. Eur Respir J 2018 52: PA2911.

10. Bosi M, Milioli G, Fanfulla F, et al. OSA and prolonged oxygen desaturation during sleep are strong predictors of poor outcome in IPF. Lung 2017; 195: 643-51.

11. Mermigkis C, Bouloukaki I, Schiza SE. Sleep as a new target for improving outcomes in idiopathic pulmonary fibrosis. Chest 2017; 152: 1327-38.

12. Tudorache V, Traila D, Marc M, et al. Impact of moderate to severe obstructive sleep apnea on the cognition in idiopathic pulmonary fibrosis. PLoS One 2019; 14: e0211455.

13. Lederer DJ, Jelic S, Bhattacharya J, Basner RC. Is obstructive sleep apnea a cause of idiopathic pulmonary fibrosis? Arch Pathol Lab Med 2012; 136: 470.

14. Toumpanakis D, Kastis GA, Zacharatos P, et al. Inspiratory resistive breathing induces acute lung injury. Am J Respir Crit Care Med 2010; 182: 1129-36.

15. Ichimura H, Parthasarathi K, Quadri S, Issekutz AC, Bhattacharya J. Mechano-oxidative coupling by mitochondria induces proinflammatory responses in lung venular capillaries. J Clin Invest 2003; 111: 691-9.

16. Glucksberg MR, Bhattacharya J. Effect of alveolar and pleural pressures on interstitial pressures in isolated dog lungs. J Appl Physiol (1985) 1991; 70: 914-8.

17. Al-Alawi A, Mulgrew A, Tench E, Ryan CF. Prevalence, risk factors and impact on daytime sleepiness and hypertension of periodic leg movements with arousals in patients with obstructive sleep apnea. J Clin Sleep Med 2006; 2: 281-7.

18. Bixler EO, Kales A, Vela-Bueno A, Jacoby JA, Scarone S, Soldatos CR. Nocturnal myoclonus and nocturnal myoclonic activity in the normal population. Res Commun Chem Pathol Pharmacol 1982; 36: 129-40. 
19. Hornyak M, Feige B, Riemann D, Voderholzer U. Periodic leg movements in sleep and periodic limb movement disorder: prevalence, clinical significance and treatment. Sleep Med Rev 2006; 10: 169-77.

20. Yalın OÖ, Yılmaz İA, Sungur MA, Doğu O. Obstructive sleep apnea syndrome, periodic limb movements and related factors. Turk J Neurol 2015; 21: 90-4.

21. Zhang XB, Zen HQ, Lin QC, Chen GP, Chen LD, Chen H. TST, as a polysomnographic variable, is superior to the apnea hypopnea index for evaluating intermittent hypoxia in severe obstructive sleep apnea. Eur Arch Otorhinolaryngol 2014; 271: 2745-50. 